\section{Depressive symptoms among adolescent students in Greek high schools}

\author{
Vasiliki Zacharopoulou, 1 Maria Tsironi, ${ }^{2}$ \\ Sofia Zyga,2 Fotini Gialama, ${ }^{3}$ \\ Georgia Zacharopoulou, 4 \\ Ilias Grammatikopoulos, 5 \\ Nikolaos Avraam, 6 \\ Panagiotis Prezerakos 2 \\ 1Secondary Education School, \\ Megalopolis; 2Department of Nursing, \\ University of Peloponnese, Sparta; \\ 3Department of Health Services \\ Organisation and Management, National \\ School of Public Health, Athens; 4PHC \\ Unit, EOPYY, Kalamata; ${ }^{5}$ Private Practice, \\ Veroia; ${ }^{5}$ Social Cooperative Athina-Elpis, \\ 8th Athens Mental Health Sector, Athens, \\ Greece
}

\section{Abstract}

Depressive symptoms in adolescence have been a subject of considerable controversy in terms of their nature, severity and identification. Therefore, the objective of this study was to examine the presence of depressive symptoms in Greek adolescent high school students and to explore the relationship between depressive symptoms and sociodemographic characteristics. For that purpose, a cross-sectional study design was conducted in two public schools in Megalopolis, Greece, from April 2012 to July 2012, using a self-administered questionnaire based on DSM-IV. The target population involved 222 high school students and the response rate was $74.75 \%$. Data was analyzed using trend $\chi^{2}$ test, student's t-test and bivariate analysis. The analysis of survey data was conducted using the SPSS (19.0). Main findings demonstrate that $3.6 \%$ had symptoms of major depressive episode. Furthermore, depressive symptoms were significantly higher in girls, while statistically significant relationships were found between students' physical $(\mathrm{P}<0.01)$ and mental health $(\mathrm{P}<0.008)$, students' experiences in school $(\mathrm{P}<0.02)$, students' experiences with friends $(\mathrm{P}<0.008)$ and the frequency of depressive symptoms. Overall, the study results reveal that depressive symptoms can occur in adolescents. Early diagnosis, as well as the need for psychological care at adolescence is necessary for the prevention of major depressive disorders.

\section{Introduction}

Depression represents a major mental health problem that affects more than 350 million people across the world. ${ }^{1}$ According to the World Health Survey on mental disorders, it was found that about one in twenty people reports having experienced an episode of depression during the last year. ${ }^{2}$

Depression can affect people at all ages, including children and adolescents. Several studies have shown that depressive symptoms occur over the course of childhood and adolescence and carry a great risk for the development of depressive disorders later in life..$^{3-5}$ Depression can be generally defined as a disturbance in mood, thought and body and it is characterized by varying degrees of sadness, irritable mood, disappointment, hopelessness, loneliness, guilt, self-doubt, loss of interest and pleasure in most of the activities in everyday life. According to the Diagnostic and Statistical Manual of Mental Disorders (DSM) of the American Psychiatric Association, the combination and persistence of the above symptoms on a daily basis for more than two However the combination and persistence of such symptoms on a daily basis for more than two weeks in a row and the cause of clinically significant distress or impairment in social, occupational or other important areas of functioning, can result in a major depressive episode and disorder, according to the criteria of the DSM of the American Psychiatric Association. It should be noted though that despite the fact that the DMS is one of the two widely established systems for classifying mental disorders (with the other one being the International Classification of Diseases (ICD10 ), introduced by the WHO), the main purposes of their criteria, are to provide a common language among health care professionals and to serve as guidelines that need to be informed by clinical judgment. ${ }^{6}$

Interestingly, depressive symptoms in young children are often overlooked, as they can be confused with mood swings that children often experience at this age. Nonetheless, many studies have shown that about one of every three to four children in early adolescence is estimated to meet the criteria of the DSM-IV for a mental disorder.7 Furthermore, studies report that the onset for a major depressive disorder is located between the age of 11 and 14 years, around mid-adolescence, and evolves in much higher rates in later life.8-11 More specifically, results from a study have shown that rates of depressive symptoms increased from $1 \%$ to $2 \%$ at the age of 13 and to $7 \%$ at the age of 15.12

Notably, several studies investigating the relationship between depression and gender
Correspondence: Panagiotis Prezerakos, University of Peloponnese, Nursing Department, Orthias Artemidos and Plataion, PC23100, Sparta, Greece.

Tel.: +30.273.108.9720.

E-mail: panprez@otenet.gr, panprez@uop.gr.

Key words: depression, adolescence, diagnostic self evaluation, psychopathology, depressive disorder-major.

Contributions: VZ and GZ designed the study and analyzed and interpreted the data; MT and SZ contributed to the study design and reviewed the manuscript; FG contributed to the design of the study and wrote the paper; IG critically revised the content of the manuscript; NA contributed to the analysis and interpretation of the data; PP contributed to the conception and design of the study; supervised and reviewed the manuscript; approved the final version of the manuscript and is the guarantor of the overall content.

Conflict of interests: the authors declare no potential conflict of interests.

Received for publication: 30 September 2014 Revision received: 22 November 2014.

Accepted for publication: 24 November 2014.

This work is licensed under a Creative Commons Attribution NonCommercial 3.0 License (CC BYNC 3.0).

(C) Copyright V. Zacharopoulou, 2014 Licensee PAGEPress, Italy

Health Psychology Research 2014; 2:1962

doi:10.4081/hpr.2014.1962

showed an increased rate of depression among women which was found to be emerging in middle adolescence. ${ }^{13}$ Girls report depression symptoms more frequently than boys in early adolescence, around the ages of 12 to 13 years.14-16 Consequently the present study seeks to investigate the presence of depressive symptoms among Greek adolescent students and to explore the relationship between depressive symptoms and socio-demographic characteristics.

\section{Materials and Methods}

\section{Participants}

This study was carried out in two public schools in Megalopolis, Greece, each comprising of 151 and 146 enrolled students respectively. The study population consisted of 222 students from A, B and C high school classes whose age ranged from 15 to 20 years. The collection of research data held within a four month period, from April 2012 to July 2012. 


\section{Instruments}

To identify symptoms of depression in school adolescents, the scale for depression diagnosis according to the Diagnostic and Statistical Manual for Mental Disorders (DSMIV) of the American Psychiatric Association was used. ${ }^{6}$ The DSM scale for depression is a structured self-administered checklist which rates major depressive disorders according to the Diagnostic Interview Schedule for Children (DISC 2.3C).17 The scale comprises of 28 questions covering diagnostic criteria of depression according to the diagnostic manual of mental disorders (DSM), such as depressive mood, decreased interest or pleasure, significant weight change or change in appetite, change in sleep patterns, change in activity, fatigue or loss of energy, sense of guilt and unworthiness, diminished ability to concentrate and suicidality. Furthermore, an additional questionnaire comprising of 21 questions was used, to collect data on socio-demographic characteristics of the study population such as gender, age, residential area, health and physical status, substance use, as well as parents' educational level and type of employment. Both questionnaires were taken upon permission, from a previous similar study conducted in Greece, by Chatzidimou. 18

\section{Internal validity}

The standardization and validation of the diagnostic instrument in the Greek language has been done by Chatzidimou, while she was conducting her $\mathrm{PhD}$ dissertation. ${ }^{18}$ The internal reliability of the survey instruments was tested in a pilot study. For the pilot study, 25 students from both schools and all high school classes (A, B and C) participated. Cronbach's alpha reliability coefficient was 0.94 indicating an excellent reliability. The Cronbach's alpha reliability coefficient for the total student population $(\mathrm{n}=222)$ was 0.9 , indicating also an excellent reliability.

\section{Procedure}

The use of both questionnaires on schoolchildren was held upon authorization granted by the Scientific Committee of the Greek Ministry of Education and Religious Affairs, school principals and children's parents. It should be noted though, that the permission to use the questionnaire based on the DSM scale, was granted after the exclusion of the last five questions relating to suicidality, since it was considered to be posing a risk for development of suicidal ideas to students.

\section{Statistical analysis}

Categorical variables are presented as absolute (n) and relative frequencies (\%). Associations between categorical variables were tested using $\chi^{2}$ test (chi-square test), while the differences between quantitative and dichotomous variables were tested using the Student's t-test. The level of significance was set at $\mathrm{P}<0,05$. The analysis of survey data was conducted using the Statistical Package for Social Sciences (SPSS 19.0).

\section{Results}

\section{Socio-demographic characteristics}

Socio-demographic characteristics of the sample are presented in Table 1 . The majority of the students $41.4 \%(\mathrm{n}=92)$, attended high school class A, while $32 \%(n=71)$ were in class $\mathrm{B}$ and the remaining 26.6\% ( $\mathrm{n}=59)$ were in class $\mathrm{C}$. Mean age of the study population was 17.0 (95\% CI 0.93 to 1.0) for both genders. Most of the parents' (both fathers and mothers) were high school graduates (secondary basic educational level). Almost half of the student's fathers were employed either in the public or private sector (41.6\%) while most mothers were unemployed or housewives $(69.2 \%)$.

Table 1. Baseline socio-demographic characteristics of the sample of 222 adolescent students in Greece.

\begin{tabular}{|c|c|}
\hline Characteristics & Number $(\%)$ \\
\hline $\begin{array}{l}\text { Gender }(n=222) \\
\text { Male } \\
\text { Female }\end{array}$ & $\begin{array}{l}113(51.9) \\
109(49.1)\end{array}$ \\
\hline $\begin{array}{c}\text { Age }(\mathrm{n}=222) \\
15 \\
16 \\
17 \\
18 \\
19 \\
20 \\
\end{array}$ & $\begin{array}{l}12(5.4) \\
85(38.3) \\
81(36.5) \\
39(17.6) \\
4(1.8) \\
1(0.4)\end{array}$ \\
\hline $\begin{array}{c}\text { Class }(\mathrm{n}=222) \\
\text { A } \\
\text { B } \\
\text { C }\end{array}$ & $\begin{array}{l}92(41.4) \\
71(32) \\
59(26.6)\end{array}$ \\
\hline $\begin{array}{l}\text { Father's educational level }(\mathrm{n}=216) \\
\text { Primary } \\
\text { Secondary } \\
\text { Technological educational institute/university }\end{array}$ & $\begin{array}{l}47(21.8) \\
135(62.5) \\
34(15.7)\end{array}$ \\
\hline $\begin{array}{l}\text { Father's employment type }(\mathrm{n}=185) \\
\text { Private/public sector } \\
\text { Self-employed } \\
\text { Worker/technician } \\
\text { Unemployed } \\
\text { Farmer/breeder } \\
\text { Retired }\end{array}$ & $\begin{array}{l}77(41.6) \\
42(22.7) \\
31(16.8) \\
6(3.2) \\
17(9.2) \\
12(6.5)\end{array}$ \\
\hline $\begin{array}{l}\text { Mother's educational level }(\mathrm{n}=219) \\
\text { Primary } \\
\text { Secondary } \\
\text { Technological educational institute/university }\end{array}$ & $\begin{array}{l}37(16.9) \\
148(67.5) \\
34(15.6)\end{array}$ \\
\hline $\begin{array}{l}\text { Mother's employment type }(\mathrm{n}=168) \\
\text { Private/public sector } \\
\text { Self-employed } \\
\text { Worker/technician/farmer } \\
\text { Unemployed/housewives } \\
\text { Retired }\end{array}$ & $\begin{array}{c}29(17.2) \\
19(11.3) \\
13(7.8) \\
104(61.9) \\
3(1.8) \\
\end{array}$ \\
\hline
\end{tabular}

Regarding questions on students' selfassessment, results showed that the majority of the students presented an overall good mental, emotional and physical health state. More specifically, the majority of the students had no chronic diseases (92.6\%), had not visited a specialist (doctor, psychologist, etc.) during the last year (85.2\%) nor had used drugs and/or alcohol (75.7\%). Concerning interpersonal relations, the majority of the students reported having either few or no problems at all with friends, school and family. Supplementary Table S1 presents the results on students' self-reported assessment.

\section{Depressive symptoms}

Based on the diagnostic manual of mental disorders (DSM), a person can be considered depressive when he/she presents at least 5 depressive symptoms nearly every day for more than two weeks in a row. Of the 222 students in both high schools, 16 (7.2\%) met the number, frequency and duration of symptoms of major depressive episodes, according to the DSM-IV. 
More specifically students reported depressed or irritable mood and/or loss of pleasure or interest almost every day for the last two weeks, as well as other deficiencies of thoughperception (such as guilt, loss of concentration, etc.) and of the autonomic nervous system (such as sleep disorders, psychophysical impairment, etc). Of the 16 students, 8 were excluded since it was found to either have used drugs and/or alcohol $(n=7)$ or to have experience the loss of a significant someone recently $(n=1)$.

Ages among the 8 student who presented depressive symptoms ranged from 15 to 17 , with the majority of them being at the age of 15 years. Of them six were girls and two were boys. The number and frequency of symptoms of major depressive episodes between the two genders is presented in Table 2 .

As shown in Table 2, the frequency of depressive symptoms was significantly higher in girls than boys. The symptoms that were found to be presented almost every day in four out of the six girls were discomfort, irritability, loss of interest and loss of pleasure. Other symptoms reported among these 8 students were ideas of guilt, ( 5 girls and 2 boys), ideas of unworthiness (4 girls and 1 boy), dissatisfaction with appearance (4 girls), lack of hope (4 girls), tendency for crying (3 girls and 1 boy) and insomnia ( 2 girls and 2 boys). Noteworthy, the incidence of depressive symptoms in all 222 children was also found higher in girls confirming the significant relationship between gender and depressive symptomatology, as presented in Supplementary Table S2.

According to Supplementary Table S2, statistically significant relationship was found between gender and symptoms such as: discomfort $(\mathrm{P}<0.001)$, irritability $(\mathrm{P}<0.002)$, loss of pleasure $(\mathrm{P}<0.001)$, loss of interest $(\mathrm{P}<0.02)$, insomnia $(\mathrm{P}<0.001)$, psychophysical impairment $(\mathrm{P}<0.007)$, inability to attend school $(\mathrm{P}<0.005)$, inability to look after their selves $(\mathrm{P}<0.007)$, fatigue $(\mathrm{P}<0.002)$, sense of guilt $(\mathrm{P}<0.001)$, ideas of unworthiness $(\mathrm{P}<0.001)$, dissatisfaction with appearance $(\mathrm{P}<0.001)$, tendency for crying $(\mathrm{P}<0.001)$, diminished ability to concentrate $(\mathrm{P}<0.02)$ and diminished ability to think $(\mathrm{P}<0.002)$. Furthermore, results from the bivariate analysis showed a statistically significant relationship between students' physical $(\mathrm{P}<0.01)$ and mental health $(\mathrm{P}<0.008)$, students experiences in school $(\mathrm{P}<0.02)$ as well as experiences with friends $(\mathrm{P}<0.008)$ and the frequency of depressive symptoms. More specifically the frequency of depressive symptoms was lower in students with a good mental and physical health state and in students who reported having no problem at school or with their friends.

\section{Discussion}

The purpose of the present study was to investigate the presence of depressive symptoms among adolescent students in two Greek high schools and to explore the relationship between depressive symptoms and various demographic characteristics.

According to the findings of this study, depressive symptoms based on the self Diagnostic and Statistical Manual for Mental Disorders scale were presented in $3.6 \%(\mathrm{n}=8)$ out of 222 students in both schools (with no prior substance abuse or loss of a significant someone). It should be noted though that students who met the number, frequency and duration of the symptoms of a major depressive episode were not considered to be depressive if there were signs of systemic disease, intoxication and bereavement.

Despite the fact that the study population involved in the present study is relatively small, the fact that 8 out of 222 students were found to meet the criteria of the DSM scale is interesting. These results may be considered consistent with that of other studies which reveal that one out of three adolescents experience a depressive symptom. ${ }^{19}$ Similarly in a large survey of 1326 adolescents between the ages of $13-15$ it was found that $20.3 \%$ of them present depressive symptoms. ${ }^{20}$

Regarding the frequency of the symptoms on both genders, it was found a statistically significant relationship between 15 symptoms of the DSM scale and gender. More specifically symptoms such as discomfort, irritability, loss of interest and pleasure, insomnia, psychophysical impairment, inability to attend school or look after their selves, fatigue, ideas of guilt and unworthiness, dissatisfactions with appearance, tendency for crying, inability to concentrate and think, were found to be presented much more frequently in girls than boys. Similarly, the frequency of symptoms among the 8 students who were considered depressive (based on the DSM scale), was found also higher in girls $(n=6)$ than boys (2).

The later finding appears consistence with other similar studies which investigate the relationship and effect of gender to the frequency of depressive symptoms. ${ }^{13-15,21,22}$ The higher frequency of depressive symptoms in girls is likely to be related to psychosocial factors, such as interpersonal relations. ${ }^{23-25}$ However, aside the psychosocial factors, it appears that biological changes caused by puberty, are to some extent also responsible for the incidence of depression symptoms in girls. ${ }^{26}$ During puberty girls experience greater biological challenges compared to boys, such as rapid growth in height, gain in body fat and dramatic increase in estrogen and progesterone production. Notably, this deregulation of the ovarian hormones (e.g. estrogen and progesterone) is considered to play a key role in the development of depressive symptoms. ${ }^{14}$ Finally, concerning the age of the study population, depressive symptoms at young ages poses a great risk for development of depressive disorder later in life. ${ }^{11,16,27}$

\section{Study limitations}

Limitations of the current study have to taken under consideration while interpreting the presented results. First of all, the relatively small sample size along with its geographical location limits the generalization of our results. The extent to which results could have been comparable or different with samples in different Greek regions is difficult to be interpreted.

Another limitation is the fact that as soon as the study was conducted and results were retrieved an update of the DSM scale was available (DSM-5). In the updated DSM-5, of the important changes are the bereavement feelings exclusion and the Disruptive Mood Dysregulation Disorder (DMDD) addition, in the depressive disorders' section. However as reported in the Discussion section, students were not considered depressive if there were signs of bereavement and thus the exclusion of bereavement does not affect the results of the present study. On the other hand, the addi-

Table 2. Number and frequency of symptoms of major depressive episodes.

\begin{tabular}{|c|c|c|c|c|c|c|}
\hline \multirow[t]{2}{*}{ Symptoms } & \multicolumn{2}{|c|}{ Girls (n) } & \multicolumn{2}{|c|}{ Boys (n) } & \multicolumn{2}{|c|}{ Total (n) } \\
\hline & Almost every day & Frequently & Almost every day & Frequently & Girls & Boys \\
\hline Discomfort & 4 & 2 & 1 & 0 & 6 & 2 \\
\hline Irritability & 4 & 0 & 2 & 0 & 6 & 2 \\
\hline Loss of pleasure & 2 & 2 & 1 & 1 & 6 & 2 \\
\hline Loss of interest & 4 & 1 & 1 & 0 & 6 & 2 \\
\hline
\end{tabular}


tion of the DMDD is important in using the DSM diagnostic tool for classification and psychiatric diagnosis. However, since the objective of the present study is the examination of the presence of depressive symptoms and not the diagnosis, our results are not affected. Furthermore it is important to point out that the study is based on adolescents who attend school, leaving out those who either have left or have been expelled from school or those adolescents who live in institutions or orphanages, who might also present depressive symptoms.

Clearly the validity and reliability of selfreported data on sensitive and highly stigmatized behaviors such as substance abuse might be questioned. Consequently it is possible that adolescents did not report such behaviors or gave unreliable answers.

\section{Conclusions}

Depressive symptoms can occur in adolescents and are related to sociodemographic characteristics, such as gender and age as well as children's physical and mental health and experiences both with friends and in school, based on the results of the present study. Early and accurate diagnosis, evaluation and treatment of emotional disorders, as well as the need for psychological care at the early ages of adolescence until adulthood are necessary for the prevention of major depressive disorders. The experience of a major depressive disorder at young ages can greatly affect the course of adolescents' life not only in relation to mental and physical health but also in relation to their social life.

\section{References}

1. WHO. Depression. A global public health concern. 2012. Available from: http://www.who.int/mental_health/management/depression/who_paper_depression_wfmh_2012.pdf

2. Kessler RC, Haro JM, Heeringa SG et al., The World Health Organization world mental health survey initiative. Epidemiol Psichiatr Soc 2006;15:161-6.

3. Compas BE. Depression in children and adolescents. In: Mash EJ, Terdal LG, eds. Assessment of childhood disorders. New York: Guilford Press; 1997. pp 127-229.

4. Fleming JE, Offord DR. Epidemiology of childhood depressive disorders: a critical review. J Am Acad Child Adolesc Psychiatry 1990;29:571-80.

5. Petersen AC, Compas BE, Brooks-Gunn J, et al. Depression in adolescence. Am Psychol 1993;48:155-68.

6. American Psychiatric Association. Diagnostic and statistical manual of mental disorders. 4th ed. Washington DC: American Psychiatric Association; 2000.

7. Costello EJ, Mustillo S, Erkanli A, et al. Prevalence of psychiatric disorders in childhood and adolescence. 2003;60:83744.

8. Wade TJ, Cairney J, Pevalin DJ. Emergence of gender differences in depression during adolescence: national panel results from three countries. J Am Acad Child Adolesc Psychiatry 2002; 41:190-8.

9. Cole DA, Martin JM, Peeke LA, et al. Children's over- and underestimation of academic competence: a longitudinal study of gender differences, depression, and anxiety. Child Dev 1999;70:459-73.

10. Lewinsohn PM, Rohde P, Seeley JR, Fischer SA. Age-cohort changes in the lifetime occurence of depression and other mental disorders. J Abn Psychol 1993;102: 110-20.

11. Hankin BL. Adolescent depression: description, causes, and interventions. Epilepsy Behav 2006;8:102-14.

12. Lewinsohn PM, Moerk KC, Klein DN. Epidemiology of adolescent depression. Econom Neurosci 2000;2:52-68.

13. Petersen AC, Sarigiani PA, Kennedy RE, Adolescent depression: why more girls? J Youth Adolesc 1991;20:247-71.

14. Nolen-Hoeksema S, Girgus JS. The emergence of gender differences in depression during adolescence. Psychol Bull 1994;115: 424-43.

15. Wichstrom L, The emergence of gender difference in depressed mood during adolescence: the role of intensified gender socialization. Dev Psychol 1999;35:232-45.

16. Twenge JM, Nolen-Hoeksema S. Age, gender, race, socioeconomic status and birth cohort difference on the children's depression inventory: a meta-analysis. J Abn
Psychol 2002;111:578-88.

17. King CA, Katz SH, Ghaziuddin N, et al. Diagnosis and assessment of depression and suicidality using the NIMH diagnostic interview schedule for children (DISC2.3). J Abnorm Child Psychol 1997;25:17381.

18. Chatzidimou S. Depression in adolescence: an epidemiological approach, in School of Philosophy. PhD dissertation. Faculty of Philosophy, Pedagogy and Psychology, National and Kapodistrian University of Athens, 1997.

19. Spear LP. The adolescent brain and agerelated behavioral manifestations. Neurosci Biobehav Rev 2000:417-63.

20. Madianos MG, Gefou-Madianou D, Stefanis CN. Depressive symptoms and suicidal behavior among general population adolescents and young adutls across Greece. Eur Psychiatry 1993;8:139-46.

21. Brooks-Gunn J, Warren MP. Biological and social contributions to negative affect in young adolescent girls. Child Dev 1989; 60:40-55.

22. Hankin BL, Abramson LY. Development of gender differences in depression: description and possible explanations. Ann Med 1999;31:372-9.

23. Cicchetti D, Rogosch FA. A developmental psychopathology perspective on adolescence. J Consult Clin Psychol 2002;70:6-20.

24. Knopf D, Park J, Mulye T. The mental health of adolescents: a national profile. National Adolescent Health Information Center, University of California, San Francisco, 2008.

25. Larson RW, Moneta G, Richards MH, Wilson S. Continuity, stability, and change in daily emotional experience across adolescence. Child Dev 2002;73:1151-65.

26. Zahn-Waxler C, Klimes-Dougan B, Slattery MJ. Internalizing problems of childhood and adolescence: prospects, pitfalls, and progress in understanding the development of anxiety and depression. Dev Psychopathol 2001;12:443-66.

27. Dunn V, Goodyer IM. Longitudinal investigation into childhood- and adolescenceonset depression: psychiatric outcome in early adulthood. Br J Psychiatry 2006;188: 216-22. 